\title{
INDOOR AIR POLLUTION: BTEX IN OCCUPATIONAL ENVIRONMENTS
}

\author{
ISRAEL FELZENSZWALB ${ }^{1}$, ELISA RAQUEL ANASTÁCIO FERRAZ ${ }^{2}$, \\ ANDREIA DA SILVA FERNANDES ${ }^{1}$, RONALD DA SILVA MUNIZ ${ }^{2}$, \\ IZABELA BATISTA DE SOUZA MATOS ${ }^{2}$, EDUARDO MONTEIRO MARTINS ${ }^{1}$ \\ \& SERGIO MACHADO CORREA ${ }^{1}$ \\ ${ }^{1}$ Universidade do Estado do Rio de Janeiro, Brazil, \\ ${ }^{2}$ Universidade Federal Fluminense, Brazil
}

\begin{abstract}
The BTEX group (benzene, toluene, ethyl benzene and xylene) is part of the list of volatile organic compounds which cause damage to a worker's health, especially in an indoor occupational environment, where these substances dissipate with greater difficulty. Thus, the present work evaluated the concentrations, mutagenicity and cytotoxicity of the BTEX group in the indoor air of workshops involving painting and varnishing. The chemical analyses were carried out using HPLC coupled to mass spectrometry. The mutagenic and cytotoxicity potentials were determined using the Salmonella/microsome and WST/LDH assays, respectively. The concentrations of each constituent of the BTEX group were below the limits established by the National Institute for Occupational Safety and Health (NIOSH) and toluene presented the highest value. Moreover, these compounds did not induce mutagenic activity in the TA98 and TA100 Salmonella typhimurium strains either in the presence or absence of metabolization, and no cytotoxic effects were observed in the A549 human lung cells. These results may be related to the low BTEX values found in the occupational environment, as can be seen in some other studies. Nevertheless, at low concentrations these compounds may cause toxicity by a pathway not investigated in this study or may have interacted with other non-monitored air constituents, reducing their toxicity. The present study sought to obtain more information and clarifications regarding occupational exposure to BTEX, contributing to the risk assessment of the workers exposed to these substances.
\end{abstract}

Keywords: air quality, BTEX, exposure, indoor, mutagenicity, toxicity.

\section{INTRODUCTION}

Benzene, toluene, ethyl benzene and xylene (BTEX) are volatile compounds used by the chemical industry to prepare raw materials to manufacture pesticides, plastic, synthetic fibers, solvents, paints, foundries, electronics and pharmaceuticals [1]. These compounds, tend to accumulate in the indoor occupational environment, exposing the workers to their risks [2]-[4]. Previous studies suggested that prolonged exposure to chemical pollutants, such as BTEX from different sources in occupational environments is one of the major factor in the deterioration of workers' health [5], [6]. Some professions are more at risk in terms of occupational health, such as professionals who work with paints, glues and solvents, amongst other BTEX sources [7]-[10]. Thus, considering the use of BTEX in several industrial segments, its difficulty in dispersing in these environments, its toxic potential and the permanence of the worker for extended periods of time in the work place [11], [12], it is important to monitor these compounds in the occupational environment. Although there are previous reports on the toxicity of the BTEX constituents [13]-[15], there is little information about the toxicity of BTEX as a group.

The present study aimed to monitor the BTEX concentrations in indoor and outdoor air in a very common work environment in paint and varnish workshops, and to assess its mutagenic and cytotoxic potential using different biological models. 


\section{MATERIALS AN METHODS}

\subsection{Chemicals and cell culture}

The Ham's F12 medium was purchased from Thermo Fisher Scientific Inc. (Waltham MA, USA). Cell Proliferation Reagent WST-1 (Cat. No. 05015944 001) and Cytotoxicity detection kit (LDH, Cat. No. 11644793 001) were purchased from Roche, Mannheim, Germany. A549 lung carcinoma cell line was kindly provided by Dr.José Carlos Pelielo de Mattos (Department of Biophysics and Biometry, Roberto Alcantra Gomes Biology Institute, University of the State of Rio de Janeiro, Rio de Janeiro, RJ, Brazil). The S9 fractions were obtained fom Moltox Inc., Boone,NC (USA) and was prepared from the livers of male Sprague-Dawley rats, pre-treated with a polychlorinated biphenyl mixture (Aroclor 1254). HPLC-grade solvents were purchased from Merck (Darmstadt, Germany) and were filtered through nylon $0.45-\mathrm{mm}$ pore size filters (Millipore Corp.). The mobile phases and all solutions were membrane filtered (nylon, $0.22-\mathrm{mm}$ pore size). Highly purified water with a resistivity of $18.1 \mathrm{MV}-\mathrm{cm}$ (Barnstead/ Thermolyne, Dubuque, IA, USA) was used throughout the preparations and assays. The analytical grade dimethyl sulfoxide (DMSO, CAS 67-68-5) were purchased from Merck (Darmstadt, Germany). High Concentration BTEX Mix, Bacto $^{\text {TM }}$ (CAS 9002-18-0), tryptone (CAS 91079-40-2), yeast extract (CAS 8013-01-2), biotin (CAS 58-85-5), histidine (CAS 71-00-1), Sodium phosphate monobasic monohydrate (CAS 10049-21-5), sodium phosphate dibasic (CAS 7558-79-4), 4-nitroquinoline-N-oxide (4-NQO, CAS 56-57-5), sodium azide (SA, CAS 26628-22-8), 2-aminoanthracene (2-AA, CAS 613-13-8), fetal bovine serum, trypsin-EDTA solution and penicillin-streptomycin were purchased from Sigma-Aldrich (St. Louis, Mo., USA). All chemicals and solvents were of analytical grade or the highest grade commercially available. Dichloromethane GC grade was purchased from Aldrich (414751), methanol spectrophotometric grade was purchased from Sigma-Aldrich (154903). BTEX mix was a $2000 \mu \mathrm{g} \mathrm{L} \mathrm{mL} \mathrm{mL}^{-1}$ certified reference material purchased from Supelco (CRM47993).

\subsection{Sampling}

Air samples were collected in painting and varnishing workplaces belonging to the area of preventive, corrective and operational maintenance of the Rio de Janeiro State University (UERJ) buildings. The UERJ building has 24 floors and the study area is located on the ground floor. It is an area without public circulation, reserved only for workers. No forced exhaust system is employed. The existing ventilation is only by means of ceiling fans and small windows opening to an external area. The area studied has natural ventilation with small windows opening to an external area and ventilation by fans. The rooms are equipped with wall hoods that promote a mechanical exhaust and lighting by fluorescent lamps. The exhaust equipment was frequently not working and incorrect procedures were adopted, for example, the use of uncapped products. For comparison, outdoor samples were collected at a distance of 260 meters, without the influence of the activities carried out in the workshops. The varnishing workshop has a total area of $32 \mathrm{~m}^{2}$ with $3.44 \mathrm{~m}^{2}$ of window area and a height of $3.50 \mathrm{~m}$. The products used are varnish, alcohol, gasoline, turpentine, solvents, beeswax, carnauba wax and paraffin. The painting workshop has a total area of $42 \mathrm{~m}^{2}$ with $4.60 \mathrm{~m}^{2}$ of window area and a height of $3.50 \mathrm{~m}$. The products used are turpentine, solvents, PVA paint, synthetic paint, lacquer and spackling. Fifteen samples were collected in duplicate from inside each of the workshops between the months of December 2014 and February 2015, between $8 \mathrm{AM}$ and $2 \mathrm{PM}$, the period of intensive work in these places. The four air pumps 
(KNF UNMP 850KNDC) operated at $700 \mathrm{~mL} \mathrm{~min}^{-1}$ for $3 \mathrm{~h}$ using double bed (100/50 mg) coconut shell cartridges (SKC 226-01) according to several previous studies [4], [16]-[19].

\subsection{Chemical analyses}

The samples were extracted with $1000 \mu \mathrm{L}$ of high-performance liquid chromatography (HPLC) grade dichloromethane at $-20^{\circ} \mathrm{C}$ for 10 minutes in an ultrasonic bath [16]-[18]. Chemical analyses were carried out using a Varian 450GC coupled to a Varian MS220 mass spectrometer with an HP 5 MS capillary column $(30 \mathrm{~m}, 0.32 \mathrm{~mm}, 0.25 \mu \mathrm{m})$ using helium at $1.2 \mathrm{~mL} \mathrm{~min}$. The samples were analyzed in the liquid phase with a splitless injection of 1.0 $\mu \mathrm{L}$ at $200^{\circ} \mathrm{C}$. The column temperature was initially held at $40^{\circ} \mathrm{C}$ for $4 \mathrm{~min}$, and then raised at $10^{\circ} \mathrm{C} \mathrm{m^{-1 }}$ to $220^{\circ} \mathrm{C}$. The transfer line, manifold and ion trap were operated at $280^{\circ} \mathrm{C}$, $50^{\circ} \mathrm{C}$ and $250^{\circ} \mathrm{C}$, respectively. Selective ion monitoring was operated using 78,91 , and 109 $\mathrm{m} / \mathrm{z}$ as the principal ions. The analytical curves were prepared using a standard BTEX mixture in methanol with triplicate injections between 100 and $20,000 \mu \mathrm{g} \mathrm{L}^{-1}$, as well as a solvent blank. The detection and quantification limits for all the BTEX samples were 12 and $35 \mu \mathrm{g} \mathrm{L}^{-1}$, respectively. The determination coefficients for all the BTEX samples were greater than 0.99 . The samples were extracted as before [20] with some modifications. On the day of exposure, the active carbon beads of each cartridge containing BTEX, in hermetically sealed vials, were placed in contact with $1 \mathrm{~mL}$ of DMSO for 30 minutes in an ultrasonic bath. A pool of all the samples obtained from each workshop was then prepared and the experiments carried out.

\subsection{Salmonella/microsome assay}

The pre-incubation protocol in the absence and presence of exogenous metabolism ( $\mathrm{S} 9,4 \%$ w/v mix) was carried out using the screening TA98 (hisD3052, rfa, $\Delta$ bio, $\Delta$ uvrB and pKM101) and TA100 (hisG46, rfa, $\Delta$ bio, $\Delta$ uvrB and pKM101) Salmonella typhimurium strains, which have been shown to identify approximately $90 \%$ of the mutagens in a population containing about $35 \%$ mutagenic chemicals [22]. Briefly, $100 \mu \mathrm{L}$ aliquots of each Salmonella culture $\left(10^{9}\right.$ cells $\left./ \mathrm{mL}\right), 100 \mu \mathrm{L}$ of different concentrations of the BTEX extract diluted in DMSO $(6.25 \%, 12.5 \%, 25 \%, 50 \%$ and $100 \%)$ and $500 \mu \mathrm{L}$ of $0.2 \mathrm{M}$ phosphate buffer ( $\mathrm{pH}$ 7.4) were mixed for the assay in the absence of metabolic activation, or the same volume of the $\mathrm{S} 9$ mixture for the assay in the presence of metabolic activation, and incubated at $37^{\circ} \mathrm{C}$ for 20 minutes with shaking $(150 \mathrm{rpm})$. An aliquot of $2.0 \mathrm{ml}$ molten top agar supplemented with biotin and a trace of histidine was then added to each tube, and the mixture homogenized and poured into a petri dish containing $20 \mathrm{~mL}$ of minimal agar. The plates were incubated for 72 hours at $37^{\circ} \mathrm{C}( \pm 0.5)$ and the test was carried out in triplicate. DMSO was used as the negative control and the positive controls in the absence of S9 were: $0.5 \mu \mathrm{g} / \mathrm{plate}$ of 4NQO for TA98 and $5 \mu \mathrm{g} /$ plate of SA for TA100. For the two strains, in the presence of S9, the positive control was 2 -AA $(2.5 \mu \mathrm{g} /$ plate). The toxicity was evaluated from the background growth. All strains used in the present work are from our laboratory collection.

\subsection{Cytotoxicity assay}

The A549 lung carcinoma cell line was cultured in Ham's F12 medium containing 10\% heat inactivated fetal bovine serum and $1 \%$ penicillin/streptomycin $(10.000 \mathrm{U}: 10 \mathrm{mg} / \mathrm{mL})$ at $37^{\circ} \mathrm{C}$ with $5 \% \mathrm{CO}_{2}$. The BTEX pool extracted with DMSO and collected from the painting and vanishing workshops, was diluted in F12 medium such that less than $0.1 \%$ of DMSO remained in the culture medium. Thus, $4 \times 104$ A549 cells grown in monolayers were seeded 
into each well of a sterile flat-bottomed 96-well plate, and incubated with $6.25 \%, 12.5 \%$, $25 \%, 50 \%$ and $100 \%$ of the BTEX pool for 24,48 and 72 hours. The negative control was $0.1 \%$ DMSO and $2 \%$ Triton-X100 the positive control.

\subsection{WST-1 assay}

The WST-1 assay uses the highly water-soluble tetrazolium salt (4-[3-(4-iodophenyl)-2-(4nitrophenyl)-2H-5-tetrazolium]-1,3-benzene disulfonate) to determine the number of viable cells after exposure to BTEX. This salt is reduced by the mitochondrial dehydrogenases of the live cells giving a yellow product which is soluble in the medium used in the cell culture. Briefly, after the treatments, $10 \mu \mathrm{L}$ of the WST-1 reagent were added to $90 \mu \mathrm{L}$ of the cell cultures, which were maintained at $37^{\circ} \mathrm{C}$ and $5 \% \mathrm{CO}_{2}$ for 3 hours, and the absorbance measured at $450 \mathrm{~nm}$ using a Polaris Microplate Reader (Celer, Brazil) according to the manufacturer's recommendations. The higher the absorbance the greater is the activity of the mitochondrial dehydrogenases and the greater the viability of the cells. The results were expressed as the percentage of the negative control, which was designated as having $100 \%$ viability.

\subsection{LDH assay}

After treatment with BTEX, the cell membrane integrity was assessed from the release of intracellular lactate dehydrogenase (LDH). For this was used, in which LDH oxidizes the buffered l-lactate substrate at $\mathrm{pH} 9.4$ in the presence of $\mathrm{NAD}^{+}$generating pyruvate and $\mathrm{NADH}, \mathrm{H}^{+}$. The catalyst (diaphorase) then transfers $\mathrm{H} / \mathrm{H}+$ from $\mathrm{NADH}^{+} \mathrm{H}^{+}$to the tetrazolium salt INT, which absorbs light at $492 \mathrm{~nm}$. Briefly, after the treatments, $100 \mu \mathrm{L}$ of the culture medium were transferred to each well of a 96 well plate, and $100 \mu \mathrm{L}$ of the kit reagent solution added. The plates were incubated for $30 \mathrm{~min}$ at $20^{\circ} \mathrm{C}$ in the light, and the reading was made at $492 \mathrm{~nm}$ using a Polaris Microplate Reader (Celer, Brazil). The higher the absorbance the greater is the release of lactate dehydrogenase and the greater the cytotoxicity. The results were expressed as percentage of lactate release of the positive control, which was designated as $100 \%$ of lactate release.

\subsection{Statistical analysis}

The results were statistically evaluated using the analysis of variance (ANOVA) and Dunnett's post hoc test, and the samples were considered positive when $p<0.05$. A multivariate correlation was carried out using R Language (Kernel 3.3.1). All assays were performed in triplicate at least two times.

\section{RESULTS AND DISCUSSION}

\subsection{BTEX in the indoor and outdoor air}

Fig. 1 shows the BTEX concentrations found inside and outside the workshops. The statistical analyses indicated that the levels of BTEX compounds in the workshop areas were all significantly higher (confidence $>95 \%$ ) than in the outdoor area. 


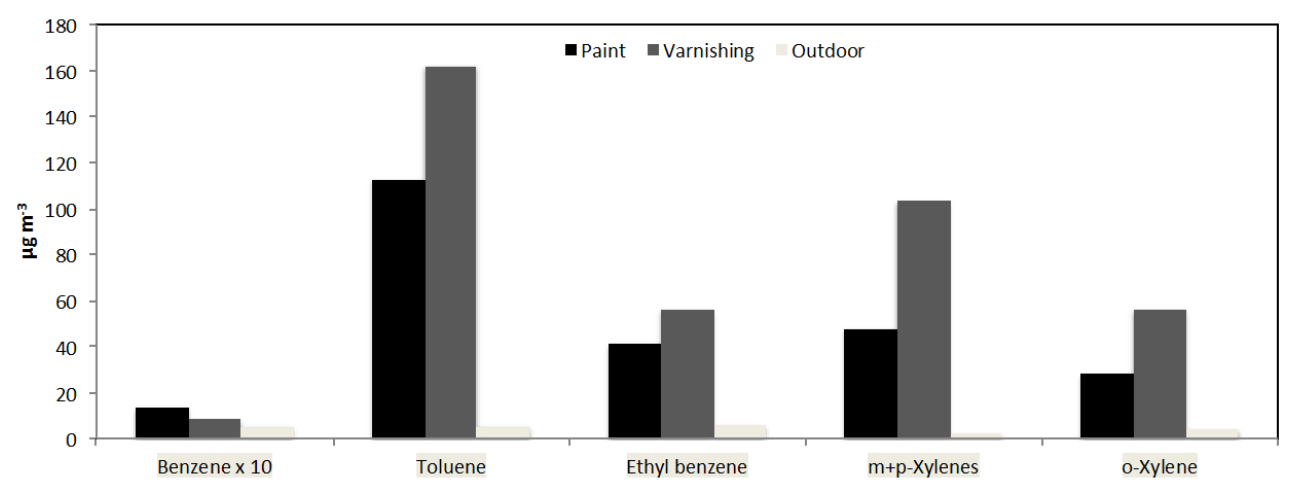

Figure 1: BTEX (benzene, toluene, ethyl benzene and xylene) concentrations obtained inside the workplaces and outdoors.

\subsection{Salmonella/microsome assay}

Figs 2 and 3 show the results obtained from the mutagenicity assessment of the air collected from the varnishing and painting workshops. It can be seen that the samples did not show mutagenic activity in the TA98 and TA100 Salmonella strains under any of the conditions evaluated.

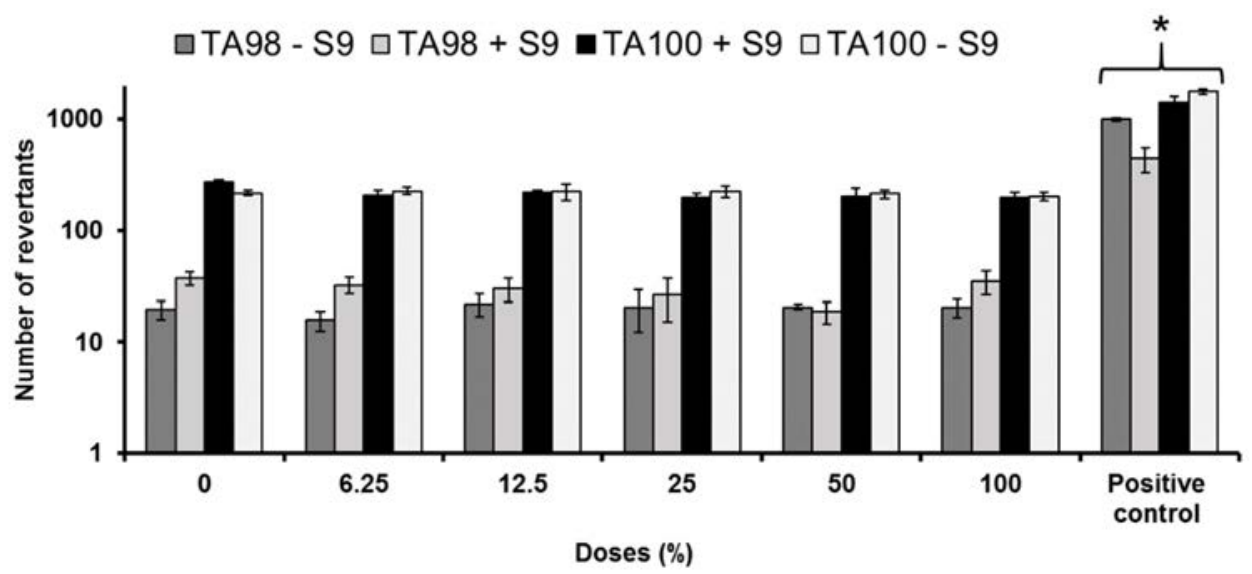

Figure 2: Response curve for BTEX (benzene, toluene, ethyl benzene and xylene) collected from the varnishing workplace when tested with the Salmonella strains TA98 and TA100 in the presence and absence of exogenous metabolic activation (S9), ${ }^{*} \mathrm{p}<0.05$. Data are representative of three independent experiments. 


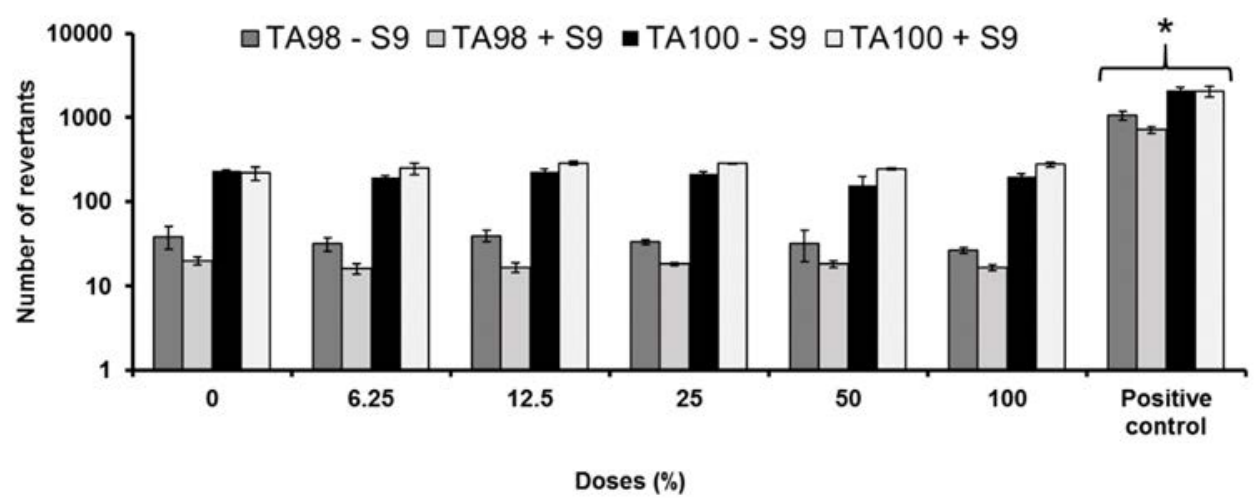

Figure 3: Response curve for BTEX (benzene, toluene, ethyl benzene and xylene) collected from the painting workplace when tested with the Salmonella strains TA98 and TA100, in the presence and absence of exogenous metabolic activation (S9). $* p<0.05$. Data are representative of three independent experiments.

\subsection{Cytotoxicity assays}

Figs 4 and 5 show the results of the cytotoxicity evaluation of the air collected in the varnishing and painting workshops respectively after 24,48 and $72 \mathrm{~h}$ of exposure. The BTEX samples did not induce cytotoxicity in the A549 cell line, neither by disrupting the dehydrogenase activity (WST-1 assay) nor by disrupting the cell membrane (LDH assay).

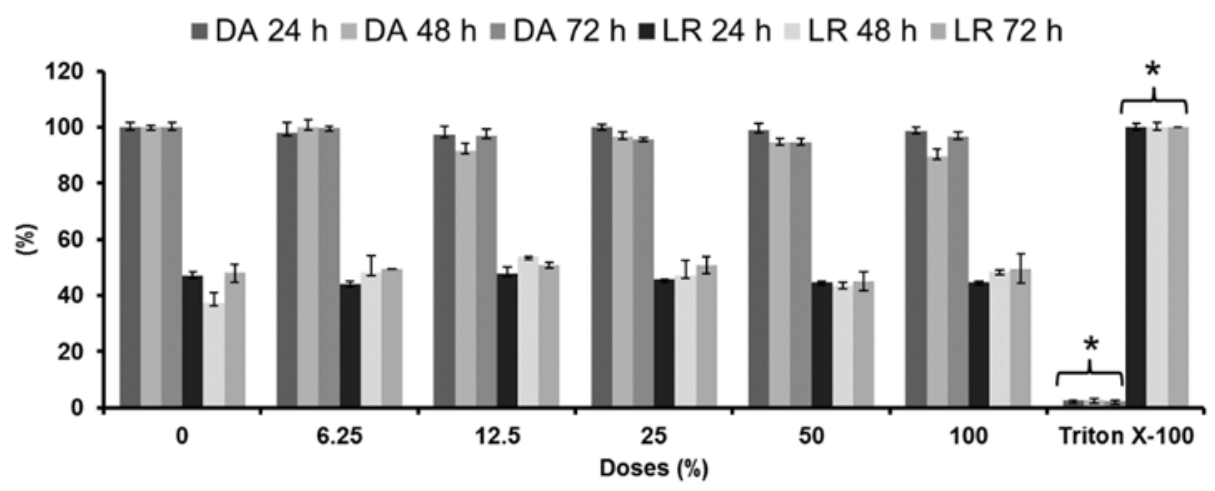

Figure 4: Effect of the BTEX (benzene, toluene, ethylbenzene and xylene) collected from the varnishing workplace on the Dehydrogenase Activity (DA) and Lactate Release (LR) of the A549 cell line after 24, 48 and $72 \mathrm{~h}$ of exposure. The asterisks indicate significant differences at $\mathrm{p}<0.05$. Data are representative of three independent experiments. 


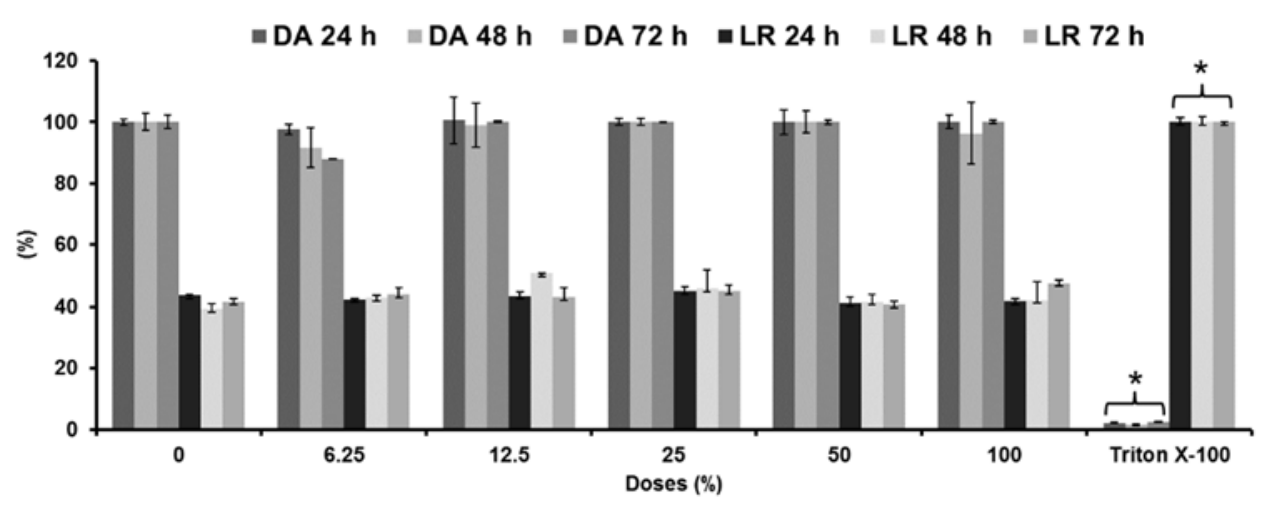

Figure 5: Effect of the BTEX (benzene, toluene, ethylbenzene and xylene) collected from the painting workplace on the Dehydrogenase Activity (DA) and Lactate Release (LR) of the A549 cell line after 24, 48 and $72 \mathrm{~h}$ of exposure. The asterisks indicate significant differences at $\mathrm{p}<0.05$. Data are representative of three independent experiments.

The largest sources of BTEX found in indoor areas are from the evaporation of gasoline and vehicle emissions [21]. Based on indoor BTEX concentrations, the highest value was obtained for toluene, since this compound is the main aromatic hydrocarbon present in many solvents and in gasoline, but this value is lower than the time weighted average value (TWA) of the NIOSH value limit $\left(377 \mathrm{mg} \mathrm{m}^{-3}\right)$. The values found for benzene were much lower than the NIOSH value limit $\left(319 \mu \mathrm{g} \mathrm{m}^{-3}\right)$, but according to the Brazilian exposure limit (NR-15) there is no safe exposure level for benzene and the value should be zero. For the other aromatics evaluated the values were also lower than the NIOSH limits $\left(434 \mu \mathrm{g} \mathrm{m}^{-3}\right)$. Even when below the limits recommended by the NIOSH, it is important to emphasize that the workers are exposed to the BTEX vapors for long period of time during the working day, and thus the risk assessment is very important for the health of these workers. Moreover, the BTEX concentrations found in the workshops studied were significantly higher than in the outdoor area, showing that the workers were occupationally exposed to high levels of BTEX when compared to the general population. For this reason, this study evaluated the mutagenic and cytotoxicity effects of the workshop air samples in order to estimate the risk to the workers. Based on the Salmonella mutagenicity assay, the indoor air of the workshops did not present mutagenic potential for the TA98 and TA100 Salmonella strains, which shows that these samples did not induce base-pair substitution, frameshift or transition/transversion mutations [22]. The same was observed in cytotoxicity using the A549 human lung cell line. The BTEX samples collected in the painting and varnishing workshops did not induce cytotoxicity in these cells after 24,48 and $72 \mathrm{~h}$ of exposure, neither by disrupting the dehydrogenase activity (WST-1 assay) nor by disrupting the cell membrane (LDH assay). These results may be related to the low BTEX concentrations found in the workshops. In a study carried out before [23] it was found that BTEX only increased the frequency of micro nucleated rat hepatoma tissue culture cells at the highest concentration tested $(902.34,168.70$, $40.40,11.74 \mathrm{mg} \mathrm{L}^{-1}$ for benzene, toluene, ethyl benzene and xylenes, respectively), values much higher than those found in the air of the workshops evaluated in this study. Using [24] mathematical calculations to carry out heath risk assessments for workers exposed to BTEX 
via inhalation at a landfill it was considered the effects of the individual BTEX compounds according to their carcinogenicities and found that the mean cancer risk for benzene was estimated as lower than the designated acceptable risk, while the mean non-carcinogenic risks for toluene, ethyl benzene and xylene, both individually and cumulatively, were lower than the specified level of 1.0. It was concluded that the landfill BTEX emissions did not pose a health threat to the workers at the landfill site. It is important to point out that the concentrations found were 140.3, 1271.7, 239.9 and $341.3 \mu \mathrm{g} \mathrm{m}^{-3}$ for benzene, toluene, ethyl benzene and xylenes, respectively, values much higher than those found in the present study. With respect to benzene, the only compound within the BTEX group proven to be carcinogenic to humans according to the IARC [25], in vitro tests have shown this compound has low or even no mutagenic action, although it has been shown to cause many types of genetic damage, such as clastogenic and aneugenic effects, inducing micronuclei, chromosomal aberrations, sister chromatid exchanges and DNA strand breaks. Similar results were obtained for both rodents and humans. Benzene and its biotransformation products were negative in almost all the Salmonella/microsome assays, with or without metabolic activation [13]. However, it is important to point out that the concentrations of these compound in the air, the interaction amongst them, and the biological target evaluated, are determinant for the manifestation and identification of the toxic effects induced by them. It was [26] assessed the chromosomal aberrations and frequency of micronuclei in meristematic an $F(1)$ root cells after BTEX exposure and found significant increases in frequency of both chromosomal and nuclear aberrations, while the micronucleus frequency was only increased in meristematic cells, showing the difference in cell behaviour after BTEX exposure. Others [27] showed that BTEX induced DNA damage in isolated human lymphocytes by single and double-strand breaks and oxidative base modification and [14] obtained positive results for benzene in both TA98 and TA100 strains without metabolic activation from two representative sites, a roadside and a petrol pump. Considering the cytotoxicity [20] assessed BTEX cytotoxicity to human lung cells using three different exposure methods and concluded that if there are any changes in the BTEX exposure matrixes, its mass exposure distribution in cells could differ, changing the toxicity found. Researchers [28] evaluated the cytotoxicity of BTEX metabolites in HeLa cells a found that these compounds affected the levels of the polyamines spermidine, spemine and putrescine, which are known to be important in cell proliferation, causing cytotoxicity. Probably, the low BTEX concentrations found in the workshops were responsible for the absence of toxicity reported in this study. However, at these concentrations, these compounds may cause toxicity by long-term exposure. It is important to point out that although the areas evaluated presented low BTEX concentrations, which did not present mutagenic and cytotoxic effects, workers are exposed to high levels of these compounds worldwide. In northern China, a study quantified the potential exposure to BTEX emitted by two Coke industries. Air from different areas of these industries was analyzed, and all of them presented excessive levels of these pollutants. Workers in these industries were being exposed to these compounds at higher levels than workers from other countries such as the USA [29]. Studies have shown that the air around gas stations frequently contains high BTEX concentrations. In Bangkok, Thailand, a survey with 49 workers at six gas stations found relatively high concentrations of these compounds [30]. A study [18] quantified BTEX compounds inside fitness before and after painting of the spinning room. It showed that the indoor concentrations were higher than the outdoor ones, and that after painting the rooms, these pollutants were found in even higher concentrations, obtaining a $91 \%$ increase for benzene, $907 \%$ for toluene, $182 \%$ for ethyl benzene, $121 \%$ for $\mathrm{m}+\mathrm{p}$ xylenes and $128 \%$ foro-xylene. Hence it is very important to carry out studies to assess the risk to human health, especially workers, in the face of BTEX exposure. Overall, higher 
levels of BTEX concentrations were observed in the painting and varnishing workshops as compared to the external areas, presumably due to the contribution from the products used in both these workshops, such as varnish, alcohol, gasoline, turpentine, solvents, beeswax, carnauba, turpentine, solvents, PVA paint, synthetic paint, lacquer and spackling. However, the BTEX levels found indoor were below the TWA levels specified by the NIOSH and did not induce mutagenic and cytotoxic activities, possibly due to the low values found and shortterm exposure. Despite the low risks found in this study it is important to point out that the harmful effects of these hydrocarbons on humans are well known and damage may be even greater after long-term exposure. Thus, more research is needed, with sufficient follow-up to understand the effects of long-term exposure to low levels of BTEX, in order to ensure safety in the work environment.

\section{ACKNOWLEDGEMENTS}

The authors are grateful to the Brazilian agencies Carlos Chagas Filho Research Support Foundation (FAPERJ) and the National Council for Scientific and Technological Development (CNPq) for financial support.

\section{REFERENCES}

[1] Barreto, G.E.S. et al., Investigation of toxic factors affecting cells of rat brains exposed to 3-methylcatechol. Braziliian Archives of Biology and Technology, 50, pp. 839-849, 2007.

[2] Guo, H., Murray, F. \& Wilkinson, S., Evaluation of total volatile organic compound emissions from adhesives based on chamber tests. Journal of Air and Waste Management Association. 50, pp. 199-206, 2000.

[3] Mitsakou, C., Housiadas, K., Eleftheriadis, S., Vratolis, S., Helmis, C. \& Asimakopoulos, D., Lung deposition of fine and ultrafine particles outdoors and indoors during a cooking event and a no activity period. Indoor Air, 17, pp. 143-152, 2007.

[4] Klinmalee, A., Srimongkol, K. \& Kim Oanh, N.T., Indoor air pollution levels in public buildings in Thailand and exposure assessment. Environmental and Monitoring Assessment, 156, pp. 581-594, 2009.

[5] Farshad, A., Oliaei, H.K., Mirkazemi, R. \& Bakand, S., Risk assessment of benzene, toluene, ethyl benzene and xylenes (BTEX) in paint plants of two automotive industries in Iran by using the coshh guideline. European Science Journal, 3, pp. 270276, 2013.

[6] Kumar, A., Singh, B.P., Punia, M., Singh, D., Kumar, K. \& Jain, V.K., Assessment of indoor air concentrations of VOCs and their associated health risks in the library of Jawaharlal Nehru University, New Delhi. Environmental Science and Pollution Research, 21: pp.2240-2248, 2014.

[7] Jones, A.P., Indoor air quality and health. Atmospheric Environment, 33, pp. 45354564, 1999.

[8] Guo, H., Lee, S,C., Chan, L.Y. \& Li, W.M., Risk assessment of exposure to volatile organic compounds in different indoor environments. Environmental Research, 94, pp. 57-66, 2004.

[9] Sarigiannis, D.A., Karakitsios, S., Gotti, A. \& Katsoyiannis, A., Exposure to major volatile organic compounds and carbonyls in European indoor environments and associated health risk. Environment International, 37, pp. 743-765, 2011. 
[10] Lim, S.K. et al., Risk assessment of volatile organic compounds benzene, toluene, ethyl benzene, and xylene (BTEX) in consumer products. Journal of Toxicology and Environment Health, 77, pp. 1502-1521, 2014.

[11] Sarafraz-Yazdi, A., Amiri, A.H. \& Es' haghi, E., BTEX determination in water matrices using HF-LPME with gas chromatography-flame ionization detector. Chemosphere, 71, pp. 671-676, 2008.

[12] Nourmoradi, H., Nikaeen, M. \& Khiadani, M., Removal of benzene, toluene, ethyl benzene and xylene (BTEX) from aqueous solutions by montmorillonite modified with nonionic surfactante: equilibrium, kinetic and thermodynamic study. Chemical Engineering Journal, 191, pp. 341-348, 2012.

[13] Whysner, J., Reddy, M.V., Ross, P.M., Mohan, M. \& Lax, E.A., Genotoxicity of benzene ant its metabolites. Mutation Research, 566, pp. 99-130, 2004.

[14] Singla, V., Pachauri, T., Satsangi, A., Maharaj, K. \& Lakhani, A., Comparison of BTX profiles and their mutagenicity assessment at two sites of Agra, India. The Scientific World Journal, Online: www.hindawi.com/journals/tswj/2012/272853/, 2012.

[15] Camara-Lemarroy, C.R., Rodríguez-Gutiérrez, R., Monreal-Robles, R. \& GonzálesGonzáles, J.G., Acute toluene intoxication-clinical presentation, management and prognosis: a prospective observational study. BMC Emergency Medicine, 15, pp. 19$25,2015$.

[16] Corrêa, S.M., Arbilla, G., Marques, M.R.C. \& Oliveira, K.M.P.G., The impact of BTEX emissions from gas station into the atmosphere. Atmospheric Pollution Research, 3, pp. 163-169, 2012.

[17] Martins, E.M., Borba, P.F.S., Santos, N.E., Bermudez, P.T. \& Silveira, R.S., The relationship betwee solvent use and BTEX concentations in occupational environments. Environmental Monitoring and Assessment, 188, pp. 608-614, 2016.

[18] Martins, E.M., Quiterio, S.L., Corrêa, S.M., Fortes, J.D.N., Monteiro, M. \& Preste, B., BTEX inside a spinning classroom. Cadernos de Saúde Coletiva, 22, pp. 218-220, 2014.

[19] de Castro, B.P., Machado, G.S., Bauerfeldt,G.F., Fortes, J.D.N. \& Martins, E.M., Assessment of the BTEX concentrations and reactivity in a confined parking area in Rio de Janeiro, Brazil. Environment, 104, pp. 22-26, 2015.

[20] Liu, F.F., Peng, C. \& Ng, J.C., BTEX in vitro exposure tool using human lung cells: trips and gains. Chemosphere, 128, pp. 321-326, 2015.

[21] Gilman, J.B., Lerner, B.M., Kuster, W.C. \& de Gouw, J.A., Souce signature of volatile organic compounds from oil and natural gas operations in northeastern Colorado. Environmental Science \& Technology, 47, pp. 1297-1305, 2013.

[22] Mortelmans, K. \& Zeiger, E., The Ames Salmonella/microsome mutagenicity assay. Mutation Research, 455, pp. 29-60, 2000.

[23] Mazzeo, D.E., Matsumoto, S.T., Levy, C.E., de Angelis, D.F. \& Marin-Morales, M.A., Application of micronucleus test and comet assay to evaluate BTEX biodegradation. Chemosphere, 90, pp. 1010-1036, 2013.

[24] Durmusoglu, E., Taspinar, F. \& Karademir, A., Health risk assessment of BTEX emissions in the landfill environment. Journal of Hazardous Materials, 176, pp. 878$877,2010$.

[25] Benzene. IARC Monographs on the Evaluation of the Carcinogenic Risk of Chemical to Human. Online: http://monographs.iarc.fr/ENG/Monographs/vol100F/mono100F24.pdf, 2002. 
[26] Mazzeo, D.E., Fernandes, T.C. \& Marin-Morales, M.A., Cellular damages in the Allium cepa test system, caused by BTEX mixture prior and after biodegradation process. Chemosphere, 85, pp. 3-18, 2011.

[27] Chen, C.S., Hseu, Y.C., Liang, S.H., Kuo, J.Y. \& Chen, S.C., Assessment of genotoxivity of methyl-tert-butyl ether, benzene, toluene, ethyl benzene, and xylene to human lymphocytes using comet assay. Journal of Hazardous Materials, 153, pp. 351-356, 2008.

[28] Shen, Y., In vitro cytotoxicity of BTEX metabolites in HeLa cells. Archive of Environmental Contamination and Toxicology, 34, pp. 229-234, 1998.

[29] He, Q., Yan, Y., Zhang, Y., Wang, X. \& Wang, Y., Coke worker's exposure to volatile organic compounds in northern China: a case study in Shanxi Province. Environmental Monitoring and Assessment, 187, pp. 1-11, 2015.

[30] Tunsaringkarn, T., Siriwong, W., Rungsiyothin, A. \& Nopparatbundit, S., Occupational exposure of gasoline station workers to BTEX compound in Bankok, Thailand. International Journal of Occupational Environment Medicine, 3, pp. 117$125,2012$. 